\title{
O(s) sujeito(s) do/no crime: efeitos de falta, resíduos incompletos
}

The subject(s) of/in crime: absence effects, incomplete residues

\author{
Ane Ribeiro Patti ${ }^{1}$ \\ Centro Universitário Barão de Mauá \\ Lucília Maria Abrahão e Sousa ${ }^{2}$ \\ Universidade de São Paulo - USP
}

RESUMO: Neste trabalho, retomando teoricamente o modo como a noção de sujeito é trabalhada na Análise de Discurso e na Psicanálise, analisamos como são constituídos dizeres aos e dos sujeitos do/no crime em uma charge de Angeli, publicada na Folha de São Paulo e intitulada "Da FEBEM para o presídio". Mostramos como os sujeitos ali expostos na charge apagam outros sentidos de si não ligados à criminalidade e silenciam também a violência que sofrem pelo funcionamento dos Aparelhos Repressivos do Estado, sendo falar de sua dor, um quase impossível de enunciar.

Palavras-chave: Análise de Discurso; Psicanálise; Sujeito; Crime.

ABSTRACT: In this work, theoretically reviewing the way in which the concept of subject is addressed both in Discourse Analysis and Psychoanalysis, we analyze sayings to/of the subjects of/in crime, in a cartoon entitled "Da FEBEM para o presídio" ["From juvie to jail"] by Angeli, published in Folha de São Paulo. We demonstrate how the subjects in such a cartoon erase other meanings of themselves which are unrelated to crime, and silence the violence they suffer through the operation of the State's Repressive Apparatus, their pain being almost impossible to enunciate.

Keywords: Discourse Analysis, Psychoanalysis, Subject, Crime.

\footnotetext{
${ }^{1}$ Professora Assistente I. Doutora em Filosofia pela Faculdade de Filosofia e Letras de Ribeirão Preto.

2 Professora Livre Docente. Bolsista Produtividade em Pesquisa do CNPQ. Doutora em Psicologia pela Universidade de São Paulo.
} 
PATTI, Ane Ribeiro; ABRAHÃO SOUSA, Lucília Maria. O(s) sujeito(s) do/no crime: efeitos de fala, resíduos incompletos.

\section{Dizeres iniciais}

[...] por ser um escrito, é um acontecimento, se não um advento de discurso (LACAN, [1971] 2009, p. 10).

Neste pequeno advento de discurso, selecionamos um capítulo em que investigamos sobre a questão do sujeito e analisamos uma charge sobre crianças e jovens que têm suas vidas subjetivadas pela criminalidade. No título deste artigo, deixamos pistas do que vem por esta escrita, uma verificação investigativa de como a noção de sujeito se fragmenta e compõe efeitos de diversidade em discurso, o que nos leva a dizeres como o sujeito é singular, emerge na linguagem, artefato exclusivo da espécie humana. A vida humana por si só já é uma raridade, se olharmos rumo ao universo, e sua particularidade está nessa sua capacidade de linguagem, na/morada do sujeito. Onde o significante está, o sujeito está ausente, representando o inconsciente enquanto material de linguagem; isso porque "[...] o significante é o que representa um sujeito para outro significante, no qual o sujeito não está" (LACAN, [1971] 2009, p. 10)

Buscaremos também, a partir de uma leitura em interface com a Análise de Discurso pecheutiana (AD) fazer uma incursão sobre como o sujeito do discurso constitui-se e circula/transita/emerge num corpus de material midiático enfocando crianças que convivem com/no narcotráfico brasileiro. A AD vem contribuir de forma basilar para a compreensão do nosso objeto, principalmente porque se aproxima da releitura da obra freudiana por Lacan que, por muito tempo em seu percurso, elaborou discussões valiosas em torno do sujeito do inconsciente que emerge com seu fio-de-liga com o consciente, entre significantes, e estes com a linguagem. A partir do Seminário 10, notamos uma ênfase nessa teorização, que dá a conhecer não só o sujeito, mas o real que o compõe e o constitui no enodamento com simbólico e imaginário; com isso, lança a possibilidade de um novo movimento para cada um que se disponha a fazer um trabalho de artesão na significação e de contínua ressignificação de sua própria vida com os objetos-letras que restam após uma travessia analítica.

Algo manca, fura, escapa, falta, é por esta brecha que podemos colocar em diálogo duas teorias distintas, e é esta uma das deixas dos Seminários de Lacan, que teve consequências no corpo do texto pecheutiano* (* "Só existe causa para o que manca" (LACAN, 1998 [1964], p. 27) e "Só há causa naquilo que falha" (PÊCHEUX, 1988 [1975], p. 300). Dar a conhecer e colocar para circular a noção de sujeito (do discurso e o da psicanálise de releitura lacaniana) se faz algo urgente na atualidade, na contramão do discurso do mestre 
tão em voga em nossa sociedade pós-moderna, que dita e reedita a homogeneidade imperativa universal e o apagamento do particular e da diversidade de particulares. Sabemos, pela AD, que esta naturalização do discurso do mestre, o portador de uma verdade única, autoritária, é fruto de sucessivos sucessos de filiações nos imperativos típicos dessa modalidade de discurso, sucessos no processo de identificação das massas com esse discurso e seus efeitos pre/dominante são verificáveis nos mais diversos campos e linhas do conhecimento, em diferentes densidades, como marcas que imprimem na criança um modo de subjetivação a ser customizada de forma única e particular, no "gasto, consumo, logo, existo", aparentando uma "carteira de identidade" que tende a ser naturalizada e padronizada na vida adulta:

Neste mundo de inúmeros mundos os sintomas seguem sendo suporte de algum tipo de unidade. Passam a representar sujeitos e a oferecer identidades: AA, Mulheres que Amam Demais, Compulsivos de todo tipo etc. Cada vez menos propõe-se eliminar estes traços, mas sim identificar-se com eles. Hoje o sintoma é carteira de identidade (VIEIRA, 2008, p. 40)

E esses efeitos de [comum] unidade, de comunidades espalhadas em formas de "panelinhas", podemos exemplificar de uma forma mais geral no apressamento e imediatismo que ao capitalismo convém ditar e que o mercado propaga - e aos seus súditos-parceirosdesavisados também, materializado nas mais diversas políticas de extermínio do sujeito falante, nas estratégias administrativas que demandam as empresas para com seus empregados (aqui podemos também incluir as escolas que repetem esse modelo, convertendo seus alunos brilhantes em números e listas nos out-dores a cada recomeço de ano, propagando seu sucesso - o da escola, obviamente), tanto no cumprimento e superação de metas impossíveis quanto na exigência de eficiência e produção quantitativa; nos atendimentos da área da saúde feitos em atacado/varejo, na incansável marcha em busca da felicidade (um dos produtos ideais mais impossíveis e vendidos pelo marketing moderno), que sempre escapa, pois, "ela está lá..." conveniada a produtos diversos que se "tem que ter" e que nunca cumprem bem o que prometem; nos excessos do tudo-poder e tudo-fazer (evidentes quando observamos e reconhecemos na obesidade e na anorexia ou mesmo na drogadição, alguns dos sintomas desse excesso de mais ou de menos modernos), baseado em modelos irreais para um humano, nos modelos ditados nas mídias do "ter que" endereçadas a todos aqueles que acreditam nisso, numa significação prévia, na existência de uma pragmática ideal, numa vivificação do corpo sem a implicação subjetiva de um sujeito e árduo trabalho de construção singular e elaboração de cada um em/de/com sua vida. 
PATTI, Ane Ribeiro; ABRAHÃO SOUSA, Lucília Maria. O(s) sujeito(s) do/no crime: efeitos de fala, resíduos incompletos.

Nossa aposta aqui vai em direção ao reconhecimento do sintomal, mas em um convite à responsabilização que cada um tem na conexão com esses discursos universais, e vai principalmente, em direção ao reconhecimento do sujeito, esse elemento que faz furo, que escapa, que emerge entre significantes, que desliza nos deslocamentos discursivos, surpreendendo, e podendo fazer surgir o inesperado, furando os universais, pois há sempre uma hiância entre a coisa e suas representações. Perguntamos: quem faz o capitalismo e quem o capitalismo faz? Perpassa a criança também por esse discurso ou é atravessada por ele? Se afirmativo, como se conectam a criança, a infância, o sujeito e o narcotráfico? Quais efeitos discursivos podemos apreender dessas conexões? Assim, trabalharemos neste artigo a noção de sujeito, e mais especificamente, a noção de sujeito discursivo, conceito caro à Análise do Discurso (AD) de matriz francesa, que busca ouvir como diz o sujeito interpelado pela Ideologia e como se estabilizam os sentidos (PÊCHEUX, 1969). A partir dessa premissa, da interpelação ideológica, marcarmos alguns indícios de como alguns sentidos de criança são construídos, constituídos no discurso dos filhos e netos do tráfico, a partir da análise da charge de Angeli "Da FEBEM ao presídio".

\section{O sujeito discursivo: no entremeio da Análise de Discurso e da Psicanálise}

Ao delinearmos o campo de constituição da Análise do Discurso, alguns conceitos ganham ênfase no prelúdio teórico como anunciamos anteriormente, dentre eles, o sujeito do discurso, que entrelaça consigo outros fios conceituais da $\mathrm{AD}$, tais como o de Ideologia e ideologias, memória, heterogeneidade, esquecimento n. 1 e n. 2, etc, e nos serve para tra(n)çar um percurso em que o sujeito é travessia, é posição no discurso, faz parte da estrutura e do acontecimento discursivo (ele é feito de discurso e ele faz discurso), e aqui iremos marcar seus indícios, sua topologia, sua matriz, seus efeitos, sua relação com outros conceitos da teoria pecheutiana e com o sujeito da psicanálise lacaniana e com os sentidos em um discurso. Não se trata de reduzir aqui, o sujeito ao conceito elaborado pelos analistas do discurso, mas delimitá-lo e enfatizá-lo como sujeito com o qual trabalharemos e que é diferente do sujeito de direito, por exemplo - que é efeito de uma estrutura capitalista para viabilizar a organização, o controle e o governo dessa estrutura social - e de demais sujeitos proferidos em outros campos do saber.

O conceito de sujeito anuncia topologicamente o lugar de onde conceituamos à medida que se difere radicalmente de outros sujeitos de outros discursos teóricos, e o sujeito aqui, é 
sempre suposto. Se recorrermos ao dicionário gramatical, dentre as várias categorias de sujeito encontradas, podemos notadamente acentuar a diferença entre o sujeito do discurso e o sujeito de direito, aquele "titular de um direito" (FERREIRA, 1986, p. 1627), os sujeitos gramaticais (oculto, simples, composto, determinado, indeterminado, zero) e o sujeito musical, além dos sujeitos das teorias da comunicação, e da psicologia, que são tomados como interlocutores e indivíduos, respectivamente. Segundo Orlandi (2005b, p. 50), “[... $o$ sujeito gramatical cria um ideal de completude, participando do imaginário de um sujeito mestre de suas palavras: ele determina o que diz", dessa forma, ele acha que escolhe e define o que diz, mas ele é determinado tanto por seu lugar subjetivo possível naquele determinado momento de sua enunciação quanto por sua exterioridade, pela história que o atravessa:

Não é vigente, na Análise de discurso, a noção psicológica de sujeito empiricamente coincidente consigo mesmo. Atravessado pela linguagem e pela história, sob o modo do imaginário, o sujeito só tem acesso a parte do que diz. Ele é materialmente dividido desde sua constituição: ele é sujeito de e é sujeito à. Ele é sujeito à língua e à história, pois para se constituir, para (se) produzir sentidos ele é afetado por elas. Ele é assim determinado, pois se não sofrer aos efeitos do simbólico, ou seja, se ele não se submeter à língua e à história, ele não se constitui, ele não fala, não produz sentidos. (ORLANDI, 2005b, p. 50)

Essa noção, de forma particular, é fundamental para marcar, nos discursos, os movimentos e os sentidos de criança, filhos e netos do tráfico de drogas, e ressaltar também, ao mesmo tempo, que há algo em comum no ser falante ao falar: ele tropeça, falha, falta, é sujeito assujeitado à linguagem, e para nós, analistas, não se trata de erro gramatical, ou de fuga das ideias, nem mesmo de quo/eficiente de inteligência (QI), a falta da qual falamos vai além da criança, das condições materiais, intelectuais, é uma falta estrutural. Que isto sirva de alerta ao leitor, no sentido de chamar o leitor à sua responsabilidade no lidar com sua leitura, pois sempre falta algo a dizer sobre o sujeito, ou em outras palavras, "nunca nos parece suficiente falar do sujeito empregando uma predicação simples” (FERREIRA, 2005, p. 1). Essa mesma autora, para argumentar acerca dessa dificuldade conceitual própria ao termo relativa à falta inerente nele, e por em jogo o "realce à família conceitual do sujeito", utilizase da expressão "trama enfática do sujeito". Assim, convocando outros autores a reforçar sobre o sujeito do discurso, encontramos em Orlandi (2005b, p. 95) outro ponto de diferença: “À diferença do que pensa a Pragmática, asseveramos que o sujeito discursivo não realiza apenas atos. Se, ao dizer, nos significamos o próprio mundo, ao mesmo tempo, a realidade se constitui nos sentidos que, enquanto sujeitos, praticamos". Quanto à procedência do termo 
utilizado em AD, retornamos às filiações teóricas que embasaram as reflexões pecheutianas, sendo que, segundo Ferreira (2005, p. 2):

A categoria de sujeito procede da filosofia e ganha com Lacan um estatuto próprio ao ser introduzida com destaque no campo psicanalítico. É sempre bom lembrar, contudo, que Freud, ainda que não a nomeasse diretamente, já tratara em textos iniciais, do que seria o essencial em matéria de inconsciente. A concepção de sujeito formulada por Lacan, como um sujeito descentrado, efeito do significante que remete para um outro significante, encontra eco em outros campos das ciências humanas, como é o caso da análise do discurso. E Pêcheux não fica surdo a essa voz; muito ao contrário.

O sujeito do discurso, assim, é fruto de um entremeio entre movimentos metafóricos e metonímicos, paráfrase e polissemia, e ele significa em determinadas condições pelo viés do interdiscurso que sustenta seu dizer, inscrito pela memória, que por sua vez está inscrita nas formações discursivas, que são inscritas nas formações sociais, que se constituem nas injunções ideológicas. Ainda falando em termos epistemológicos, em stricto sensu, a raiz do termo sujeito, no latim, designa "posto debaixo" (FERREIRA, 1986, p. 1627), o que possibilita a conceituação que ganhou corpo com a $\mathrm{AD}$ e com a psicanálise, já que se trata de um sujeito dividido pela/na linguagem, interpelado pela ideologia, descentrado, clivado, gestado pela história e parido no discurso. É o elemento que faz fenda no discurso, opacificando a linguagem e sendo opacificado por ela, ao mesmo tempo em que faz elo, em um lugar intervalar, entre a linguagem, a ideologia e a psicanálise fazendo furo em cada uma dessas três instâncias, representados pelo equívoco na/para a linguagem, a contradição na/para a ideologia, e o inconsciente, na/para a psicanálise (FERREIRA, 2005), ou ainda, "posto debaixo" no sentido dos esquecimentos que o constituem.

O eu (ego na interpretação inglesa da obra freudiana ou o moi (eu, em francês), na leitura lacaniana do mesmo termo) desconhece o sujeito (Je, ou sujeito do inconsciente, o agente) que enuncia em seu próprio discurso, mas tem acesso a partes do que diz, na cadeia significante. Explicaremos melhor. Lacan (1998 [1964], p. 194) desenvolve em seu Seminário - livro 11, uma topologia para dar conta da constituição do sujeito:

Primeiro acentuei a repartição que constituo ao opor, em relação à entrada do inconsciente, os dois campos do sujeito e do Outro. O Outro é o lugar que se situa a cadeia do significante que comanda tudo que vai poder presentificarse do sujeito, é o campo desse vivo onde o sujeito tem que aparecer. 
E em termos de discurso, Lacan o define também por seu furo, pelo que lhe escapa: "[...] aquilo que se articula a partir de uma estrutura, em alguma parte da qual ele se acha alienado de maneira irredutível" (2009 [1971], p. 10). Estamos diante de duas teorias - AD e psicanálise - que apresentam pontos de contato em alguns momentos, como, por exemplo, na definição de sujeito como um filho do significante “... sujeito definido como efeito do significante" (LACAN, 1998 [1964], p.196). Jorge (2000, p. 99, apud FERREIRA, 2005, p. 3), acentua esse lugar de escansão: “[...] 'o sujeito é esse entre significantes'. É ele que liga os significantes uns aos outros". O sujeito do discurso, para AD, pode ser mapeado, notado, flagrado em seu(s) movimento(s) em determinadas marcas linguísticas. No bojo da AD, o sujeito é formalizado em relação a algumas de suas características principais: o sujeito do discurso se caracteriza por não ser empírico e, apesar de ganhar corpo na materialidade linguística, não é quantificável, não é normatizável, por não ter compromisso com as leis e normas que regem a semântica, o direito, as demais teorias. Ele emerge no discurso como sujeito faltoso, errante, desejante e passível de equívocos, ambiguidade e falhas, que se manifestam na ordem da língua e são afetados pela ideologia em dadas condições de produção (PATTI; ROMÃO, 2008).

Assim, segundo a $\mathrm{AD}$, nas relações sócio-históricas são produzidos efeitos de sentidos entre interlocutores num espaço constantemente tenso de disputas, polêmicas, repetições, rupturas e deslocamentos. O sujeito pode migrar de uma posição para outra, produzindo um efeito de sentido diferente: "Devemos ainda lembrar que o sujeito discursivo é pensado como 'posição' entre outras” (ORLANDI, 2005b, p. 49) e lembramos, segundo a mesma autora, que: "O que há é uma modulação do nosso discurso e da nossa identidade nas diferentes relações. Essa modulação se faz em direção ao para quem do discurso e a contraditoriedade, então, é a seguinte: o sujeito é o mesmo e é diferente simultaneamente" (ORLANDI, 1987, p. 189). Isso nos remete ao modo como o sujeito assume um lugar no discurso, garantindo uma imagem de si e dando ao seu interlocutor também um lugar no discurso, de modo a dizer ao outro de acordo com o que ele antecipa ser desejável e aceito. Esse processo, marcado pelo modo como o sujeito é interpelado pela ideologia, foi descrito por Pêcheux (1990) como constitutivo do discurso e é denominado jogo das formações imaginárias. 
PATTI, Ane Ribeiro; ABRAHÃO SOUSA, Lucília Maria. O(s) sujeito(s) do/no crime: efeitos de fala, resíduos incompletos.

Quadro 1 - Jogo de antecipação das formações imaginárias

\begin{tabular}{|c|c|c|}
\hline $\begin{array}{l}\text { Expressão que designa as } \\
\text { formações imaginárias }\end{array}$ & Significação da expressão & $\begin{array}{l}\text { Questão implícita cuja } \\
\text { "resposta" subentende a } \\
\text { formação imaginária } \\
\text { correspondente }\end{array}$ \\
\hline \multirow{2}{*}{$\begin{array}{l}\mathrm{I}_{\mathrm{A}}(\mathrm{A}) \\
\{ \\
\mathrm{I}_{\mathrm{A}}(\mathrm{B})\end{array}$} & $\begin{array}{l}\text { Imagem do lugar de A para o } \\
\text { sujeito colocado em A }\end{array}$ & $\begin{array}{l}\text { "Quem sou eu para lhe falar } \\
\text { assim?" }\end{array}$ \\
\hline & $\begin{array}{c}\text { Imagem do lugar de B para o } \\
\text { sujeito colocado em A }\end{array}$ & $\begin{array}{l}\text { "Quem é ele para que eu lhe } \\
\text { fale assim?" }\end{array}$ \\
\hline \multirow{2}{*}{ B } & $\begin{array}{c}\text { Imagem do lugar de B para o } \\
\text { sujeito colocado em B }\end{array}$ & $\begin{array}{l}\text { "Quem sou eu para que eu } \\
\text { lhe fale assim?" }\end{array}$ \\
\hline & $\begin{array}{c}\text { Imagem do lugar de A para o } \\
\text { sujeito colocado em B }\end{array}$ & $\begin{array}{l}\text { "Quem é ele para que me fale } \\
\text { assim?" }\end{array}$ \\
\hline $\mathrm{I}_{\mathrm{A}}(\mathrm{R})$ & $\begin{array}{c}\text { "Ponto de vista" de A sobre } \\
\text { R }\end{array}$ & "De que lhe falo assim?" \\
\hline $\mathrm{I}_{\mathrm{B}}(\mathrm{R})$ & $\begin{array}{c}\text { "Ponto de vista" de B sobre } \\
\text { R }\end{array}$ & "De que ele me fala assim?"7 \\
\hline
\end{tabular}

Dessa forma, um discurso significa à revelia da intencionalidade do sujeito, de seu exercício em tentar controlar os sentidos, de sua suposta potência de conseguir expressar aquilo que pensa, da evidência de ele ser a fonte do seu dizer e da obviedade de suas palavras em relação às coisas e ao mundo. Pela ideologia, as posições assumem um efeito de evidência e naturalização, atribuindo à voz do sujeito um efeito de colagem ao pensamento e à realidade como se tudo fosse absolutamente óbvio. É o que encontramos em Pêcheux (1988 [1975], p. 163) “o sujeito se constitui pelo ‘esquecimento' daquilo que o determina”. E continua o autor: “ 'o termo esquecimento não está designando aqui a perda de alguma coisa que se tenha um dia sabido, como quando se fala de 'perda de memória', mas o acobertamento da causa do sujeito no próprio interior de seu efeito"” (PÊCHEUX, 1988 [1975], p. 183). Assim, o autor formula dois esquecimentos constituintes do sujeito: o esquecimento número 1 centra-se no fato de que "o sujeito-falante não pode, por definição, se encontrar no exterior da formação discursiva que o domina" (PÊCHEUX, (1988 [1975], p. 173), ou seja, ele não tem como ser a fonte de seu dizer, apesar de precisar dessa ilusão para que enuncie. Enquanto que o esquecimento número 2 é aquele:

[...] pelo qual todo sujeito-falante "seleciona" no interior da formação discursiva que o domina, isto é, no sistema de enunciados, formas e sequências que nela se encontram em relação de paráfrase - um enunciado, forma ou sequência, e não um outro, que, no entanto, está no campo daquilo que poderia reformulá-lo na formação discursiva considerada. (PÊCHEUX, 1988 [1975], p. 173) 
Em outras palavras, o sujeito tem a ilusão de que consegue escolher as palavras mais adequadas para se expressar, colar seu pensamento às palavras, imprimir literalidade de sentidos aos enunciados e controlar os sentidos, que, na verdade, sempre podem ser outros.

O sentido é história. O sujeito do discurso se faz (se significa) na/pela história. Assim, podemos compreender também que as palavras não estão ligadas às coisas diretamente, nem são o reflexo de uma evidência. É a ideologia que torna possível a relação palavra/coisa. (ORLANDI, 2005b, p. 95)

Bairrão (2003, p. 11) nos aponta que a crítica que Lacan faz à filosofia é consequente da lógica em que "o sujeito não domina plenamente, ainda que o intencione, o contexto daquilo que formula. É o sujeito que, em realidade, falando é formulado pela palavra que diz", o que nos confere um outro ponto de encontro entre as duas teorias. Esta posição de Lacan foi compartilhada por Pêcheux que, como homem de seu tempo, não se contentava com as respostas que as ciências humanas de sua época davam com relação ao sujeito: "Pêcheux se angustiava com a concepção de sujeito cartesiano, sujeito do cogito, que circulava nas ciências humanas" (FERREIRA, 2005, p. 2). E aquilo que "escapava" desse cogito cartesiano, tal como os atos-falhos, lapsos, sonhos, e todos os demais representantes do inconsciente, considerados pelas teorias da comunicação como ruído, casualidade, pode encontrar nas duas teorias (AD e psicanálise) um reconhecimento, uma suposição de existência com causalidade, assentadas em normas outras, nada arbitrárias, com uma lógica de encadeamento. Freud se encarregou de inúmeras vezes tentar demonstrar isso, como neste pequeno trecho de "O delírio e os sonhos na Gradiva de W. Jensen” (FREUD, 1996 [1907], vol.V, p. 9):

Felizmente, a vida anímica possui muito menos liberdade e arbitrariedade do que supomos, e talvez, até, absolutamente não as tenha. O que no mundo exterior estamos acostumados a qualificar de casualidade, revela-se, depois, ser composto de múltiplas leis, e também o que no mundo psíquico denominamos arbitrariedade, assenta em estritas normas que, por ora, só obscuramente suspeitamos.

Vamos ressaltar este "depois" freudiano como o movimento de verificação de significação e/ou ressignificação que se faz da vida num a posteriori do acontecimento, podendo acontecer em uma análise ou fora dela, e que, trata-se do acontecimento psíquico, atualizado na transferência. E não se trata necessariamente de uma verdade concreta, um acontecimento material, mas sim, discursivo, no aqui-agora do sujeito falante, que, ao encadear sua fala num eixo associativo, poderá, sempre retroativamente, ressignificar um ponto dessa rede em que um escutador, ou analista, faça sua marca, coloque em presença uma 
alteridade. Tal movimento, por exemplo, pode irromper por alguma intervenção do analista no dizer do sujeito, estranhando, pontuando uns (e não outros quaisquer) pontos, fazendo uma amarração que chamamos por ponto-de-estofo, que se abre para outros pontos. Sabemos, através de ambas as teorias, AD e Psicanálise, da importância fundamental da falta, que se torna o lugar possível para que o sujeito seja este e tantos outros, para que deseje, deslize, desloque-se na rede significante e para que os seus sentidos de sujeito escapem, possam se tornar outros. Também registramos que há sempre um impossível no dizer, impossível de dizer, o que nos indica tanto a presença dessa falta estrutural, quanto, por consequência, a completa parcialidade das supostas verdades únicas, e dos materializados dizeres, ou, em outras palavras, do real na língua. "Se não houvesse a falta, se o sujeito fosse pleno, se a língua fosse estável e fechada, se o discurso fosse homogêneo e completo, não haveria espaço por onde o sentido transbordar, deslizar, desviar, ficar à deriva" (FERREIRA, 2005, p. 4).

Os sentidos, assim, vão circulando conforme as formações sociais (FSs) determinam as formações ideológicas (FIs), que por sua vez, determinam as formações discursivas (FDs) em que os sujeitos se inscrevem ao enunciar. E esse jogo é amarrado e, ao mesmo tempo, instável de tal forma, que as suas bordas podem se romper, deslizar, deslocar e/ou repetir a qualquer momento, por isso diz Pêcheux (1988 [1975] p. 160) que: “uma palavra, uma expressão ou uma proposição não tem um sentido que lhe seria 'próprio', vinculado a sua literalidade" (p. 161), mas sim "mudam de sentido segundo as posições sustentadas por aqueles que as empregam". E, ao nosso ver, complementamos esse trecho de Pêcheux, incluindo também a diferença que o outro faz no lugar daquele que vai escutar/ler aquele sustenta o portador da palavra, e, portanto, poderá também mudar os sentidos, invariavelmente, pois os efeitos não pertencem àquele que profere, que escreve, que põe as palavras a caminhar. Em algumas palavras, segundo Pêcheux (1988 [1975], p. 162), a formação discursiva "é o lugar da constituição do sentido" e que é determinada pelas “posições ideológicas que estão em jogo no processo sócio-histórico" (PÊCHEUX, 1988 [1975], p. 160) que constituem uma formação ideológica e essa "dissimula, pela transparência do sentido que nela se constitui, sua dependência com respeito ao 'todo complexo com dominante' das formações discursivas, intrincado no complexo das formações ideológicas" (PÊCHEUX, 1988, p. 162), esse "todo complexo com dominante" entendido como interdiscurso, segundo o próprio autor.

Furtado (2000, p. 25) nos esclarece que "Uma FD se relaciona constantemente com seu exterior", pois é o lugar da constituição do sentido, e que é o pré-construído o elemento que "permite que se estabeleça uma relação entre intradiscurso e o interdiscurso". Com essa 
concepção de sentido enquanto efeito, Orlandi (2005b, p. 52) retoma dados importantes, dando outro nome à falta da qual falamos anteriormente e marcando a noção de incompletude: “A condição da linguagem é a incompletude. Nem sujeitos nem sentidos estão completos, já feitos, constituídos definitivamente". Nesse momento, registramos a diferença capital entre a análise de conteúdo e a $\mathrm{AD}$, pois a primeira centra-se em trabalhar com a noção de transparência como se os conteúdos e sentidos estivessem claros e identificáveis no texto. Isso implica a posição que o cientista assume de mera decodificação de textos, marcada por uma estabilidade dos signos cujos significados seriam sempre os mesmos, previsíveis e identificáveis com clareza.

Considerando o papel da ideologia (e do inconsciente), o analista do discurso sempre tateia superfícies porosas, heterogêneas e instáveis pela opacidade que inscrevem. Faz o trabalho de capturar as marcas linguísticas e tecer a sua interpretação a partir de uma posição que não é única nem absoluta. Para falar sobre as FSs, FIs e FDs, Pêcheux (1990) articulou dados do Materialismo Histórico, da Psicanálise e da Linguística, marcando que o indivíduo é interpelado em sujeito pela ideologia e não se reconhece enquanto subordinado ao Outro (interdiscurso), supondo que ele poderá fiar seu discurso com autonomia, construir seu intradiscurso como se não existisse um "sistema de evidências e de significações percebidasaceitas-experimentadas" (PÊCHEUX, 1988 [1975], p. 162). Vemos aqui como o sujeito não é livre, autônomo, independente, ou melhor, como ele se constitui na luta de classes, metáfora aqui para falar de como são legitimados ou silenciados os sentidos, na tensão das disputas dos sentidos. Ancorado em uma FD, que é "dotada de fronteiras desestabilizadas" (FURTADO, 2000, p. 26), o sujeito e(m) suas diversas posições se posiciona no discurso, sendo que:

Uma FD pode, então, ser compreendida como uma unidade heterogênea, com fronteiras sujeitas a deslocamentos, sem limites certos e com a exterioridade fazendo parte de seu interior. Sendo heterogênea, uma FD abriga diferentes posições-sujeito. Essas posições estarão mais próximas ou mais distantes do sujeito do saber dessa FD, chamado por Pêcheux de forma-sujeito (FURTADO, 2000, p. 25).

Marcando bem a questão das rupturas enunciativas no fio do discurso, a heterogeneidade (conceituada por Authier-Revuz, 1998), presente entre dois enunciadores, entre as palavras e as coisas, e ainda, entre as palavras consigo mesmas, pode servir de caminho para refletirmos sobre o sujeito e sua relação com a língua: 
PATTI, Ane Ribeiro; ABRAHÃO SOUSA, Lucília Maria. O(s) sujeito(s) do/no crime: efeitos de fala, resíduos incompletos.

A prática discursiva mostra que o sujeito, quando fala, adere à formação discursiva em que está inscrito. [...] Em suma, uma posição-sujeito materializa-se e pode ser apreendida no discurso pelos saberes da FD que o sujeito mobiliza para enunciar (CAZARIN, 2005, p. 4).

E sabemos, pela teoria discursiva, que tal movimento é marcado pela heterogeneidade e pela possibilidade de os sentidos serem outros. Além disso, o assujeitamento do indivíduo aos dizeres que o constituem passaria pela operação que a ideologia faz, apagando as fontes, naturalizando os dizeres possíveis àquele sujeito naquele determinado momento de enunciação, ou seja, interpelando-o.

Inferimos também que esse trabalho da ideologia combina-se com a memória discursiva, sustentadora da possibilidade do dizível, pois, como afirma Orlandi (2005b, p. 43): "As palavras falam com outras palavras. Toda palavra é sempre parte de um discurso. E todo discurso se delineia na relação com outros: dizeres presentes e dizeres que se alojam na memória". Nessa mesma perspectiva, pontuando também a questão do discurso e de sua forma dinâmica e heterogênea de funcionar, enquanto um acontecimento, Orlandi (2005b, p. 54) recapitula que "Pela natureza incompleta do sujeito, dos sentidos, da linguagem (do simbólico) ainda que todo sentido se filie a uma rede de constituição, ele pode ser um deslocamento nessa rede".

O sujeito deste trabalho analítico emergirá nas vozes de jornalistas, cartunista, pesquisadores, com o olhar voltado para um aspecto central, a questão de como significar hoje e produzir sentidos de criança. Indagamos: criança e infantil são sinônimos? Como a criança constitui-se como sujeito? Como estamos discurivizando, enquanto sujeitos-adultos, os sujeitos-crianças na posição de trabalhadores do crime? Aparentemente a sociedade ignora, o estado não dá conta, o crime a acolhe. Mas se respondermos do lugar de analistas, colocamos o infantil no páreo, o sujeito que não tem idade, não cresce ou desenvolve, mas se constitui enquanto estrutura ainda no período da infância e se repetirá ao longo da vida do ser falante.

Voltando aos movimentos do sujeito no discurso, ao produzir ou re-produzir sentidos, é preciso considerar que o mecanismo de naturalização de dizer é produzido "na relação do histórico e do simbólico." (ORLANDI, 2005b, 46). E isso tem íntima relação com o imaginário, campo que tenta tamponar a contradição, o furo, as imperfeições, busca unidade, território fértil para as ilusórias homogeneidades. Assim, na movência de saberes, retomamos o posicionamento de Bairrão (2003) aferindo sobre a relação do ser com sua visão, que estabelece contato com as coisas, com os objetos, mas que seria a palavra (o ouvir e o escutar), que situa o sujeito numa relação de alteridade, na qual as coisas se (re)editam, são 
faladas, ressignificadas. A coisa inscreve-se na visão, em que ocorrem os embates pela completude, formações imaginárias, nas quais se promove um movimento incessante na tentativa de tamponar o furo, e os furos que o representam, que nos tornam seres castrados, feridos narcisicamente, sendo que as pessoas se inscrevem na/pela escuta/fala, no furo. $\mathrm{O}$ lugar de acolhimento do ser humano e onde as coisas se efetivam como significantes, é na linguagem, que é furada, pois é com o consentimento da entrada dela e nela, que se constituem os sujeitos.

A falta fundadora do sujeito traz à tona igualmente uma outra condição paradoxal, como nos aponta Elia - em seu livro 'O conceito de sujeito': “... ela não se produz por si mesma, mas requer o ato constituinte do sujeito para se fazer como falta" [...] (FERREIRA, 2005, p. 5).

Porém, é importante também que não nos fixemos apenas na falta, na incompletude e no furo, já que a ilusão de homogeneidade precisa ser buscada se quisermos construir um discurso, pois, “[...] o efeito de homogeneidade discursiva de uma posição-sujeito apresentase como uma ilusão necessária que permite a seu sujeito enunciador, organizar a discursividade representativa da mesma" (CAZARIN, 2005, p. 6). Ilusão essa mobilizada não apenas para o sujeito enunciar, mas assegurada pelos sentidos tidos como dominantes na sociedade atual, na busca incansável pela completude e pela inteireza das leis, das normas, dos ditos reguladores da vida moderna, no nosso caso, em relação às crianças denominadas como infratoras.

A seguir, apresentamos a análise de uma charge de Angeli em que pese um dizer sobre o sujeito-criança que está na criminalidade.

\section{Um dizer, uma criança: uma violência apagada}

Analisemos a charge de Angeli "Da FEBEM ao presídio", publicada no Jornal Folha de São Paulo, em 16 de Março de 2005. 


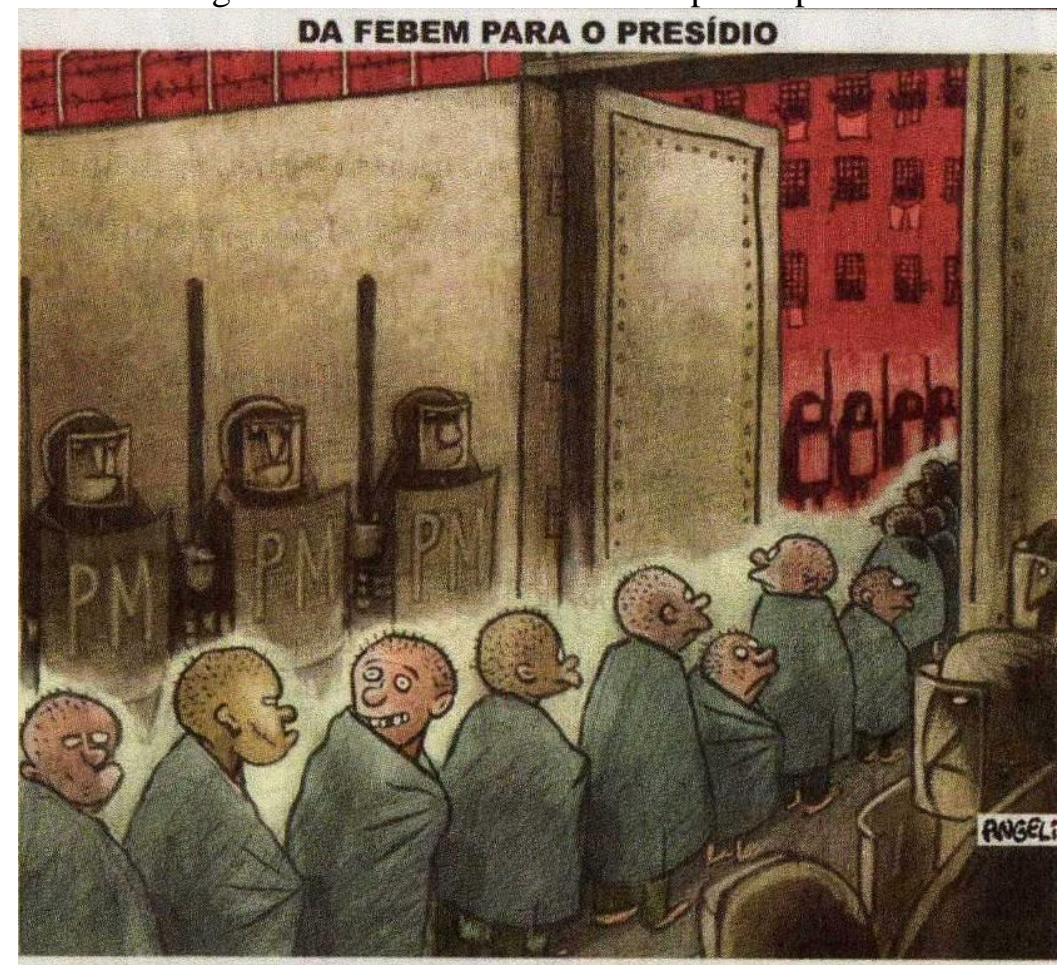

- Minha mãe não vai acreditar! Entrei na faculdade!

Fonte: Folha de S. Paulo, São Paulo, p. A-2, 16 mar. 2005.

Podemos observar a fila que aparece mantendo certa ordem; são apresentadas crianças, corpos cheios de falhas (faltam dentes, cabelos raspados, roupas substituídas por cobertores/mantas, sem sapatos), anônimas, idênticas, sem singularidade, sem proteção, como a pontuar uma voz de equívoco. Essas crianças passam dentro de uma fila mais alta, formada por adultos e marcada pela sigla " $P M$ ", nome institucional que blinda o vestir dos soldados, aqui em uma representação metafórica da Lei, do aparato que regula o controle do lado de dentro e de fora do muro da FEBEM. O garoto exclama "Minha mãe não vai acreditar!", fazendo falar um gesto de conquista, de alegria, realização de um sonho, em que ele será reconhecido pela família, ou melhor, pela mãe, como um vencedor na carreira do crime: "A mãe é uma referência afetiva para estes jovens" (FEFFERMANN, 2006, p. 326). A FD aqui presentifica um sujeito que, na evidência do sentir dor, apaga outros sentidos sobre si mesmo e sobre a violência que sofre e os substitui pela voz que sustenta o crescimento, a promoção, o sucesso, a vitória, ou "de um desejo construído pela indústria cultural” (FEFFERMANN, 2006, p. 328); desse modo, o sujeito escamoteia a violência sofrida e fala de outra coisa para não falar de dor, esse quase-impossível de enunciar. Os sentidos postos em discurso por essa charge retoma também um enunciado de um garoto (voz de criança) retirado do documentário "Falcão - Meninos do Tráfico": "Quando crescer, quero ser bandido" (ATHAYDE; BILL, 
2006a), fazendo falar os mesmos sentidos inscritos nessa formação discursiva, quais sejam, aqueles em que subir na carreira e crescer só fazem sentido se estiverem vinculados ao tráfico, uma vez que "Ao considerar a condição de sonhar desses jovens, pode-se compreender que projetar é algo muito difícil, até impensável; os seus sonhos estão relacionados com o presente; os que se sentiram traídos, sonham apenas com a possibilidade de vingar a sua história” (FEFFERMANN, 2006, p. 328).

Devemos relembrar, também aqui, o mecanismo de naturalização de sentidos interpela tanto esses meninos em sujeitos, que respondem politicamente enquanto sujeitos do discurso em um determinado momento da história posicionando-se como funcionários do tráfico, quanto o lado do Estado, representado aqui na charge pela Polícia. Althusser (1996, p. 133) postula em relação à ideologia:

[...] vamos sugerir que a ideologia "age" ou "funciona" de maneira tal que "recruta" sujeitos entre os indivíduos (ela os recruta a todos), ou que "transforma" os indivíduos em sujeitos (transforma-os a todos), por essa operação muito precisa que denominei de interpelação, e que pode ser imaginada nos moldes da mais corriqueira interpelação cotidiana da Polícia (ou de outro): "Ei, você aí!".

Assim, voltando à charge, podemos observar que o (e)feito da interpelação ideológica opera ao mesmo tempo na (re)produção de discursos que indiciam os posicionamentos possíveis dos e para os sujeitos no jogo especular que compõe uma matriz dialógica em que esses personagens se posicionam um para o outro: os meninos, encontram um lugar de reconhecimento, respondendo ao chamado: "Ei! Você aí!” de um lugar que se posicionam como parceiros da polícia, que estaria do outro lado dessa matriz, representando o Outro, e o Aparelho Ideológico do Estado jurídico, ora operando como ARE, Aparelhos Repressores do Estado (ALTHUSSER, 1996) exercendo seu poder sobre a condição cívil desses meninos. Mas são parceiros de um jeito às avessas, pela ant/agonia: só existe bandido, referido a um lugar de não-bandido, o que é reconhecido pelos próprios meninos: "Se acabar o crime, acaba a polícia. [...] Se não fosse o tráfico de drogas hoje, os polícia só ia tirar o salário deles. [...] Então o tráfico de drogas não vai acabar tão cedo" (A ODISSÉIA, 2006, p. 135). Numa leitura althusseriana, o chamado é feito da seguinte forma:

“Ei! Você aí!” Um indivíduo (nove em cada dez vezes, o indivíduo certo) se volta, acreditando/desconfiando/sabendo que é com ele, isto é, reconhecendo que "é realmente ele" quem é visado pelo chamamento. Mas, na realidade, essas coisas acontecem sem nenhuma sucessão. A existência da ideologia e o chamamento ou interpelação dos indivíduos como sujeitos são uma e a mesma coisa. (ALTHUSSER, 1996, p. 126). 
Por fim, o que aparenta evidência, na verdade, é o sucesso de várias identificações desses discursos que compõem as formações discursivas inscritas em formações ideológicas que atualizam a grande ditadora do discurso dominante, que rege o sistema capitalista no ocidente. As Formações Sociais (FS) que ditam: "vocês são o que vocês consomem, portanto, produzam capital para alimentar este consumismo e serem reconhecidos ao sol’! Esse mecanismo faz com que sejam reproduzidas as relações de produção e as relações delas derivadas, cultivando o sentido socialmente dominante de que o consumo e o gozo são a ordem imperativa para a realização; e, assim, temos como resultado a alienação do sujeito a esse discurso dominante, o que promove um mecanismo imaginário de filiação do desejo e das possibilidades de deslocamentos. É preciso marcar ainda que esse processo é constituído pelo furo e pela movência do sujeito que sempre pode ocupar um outro lugar do vir-a-ser dos (seus) sentidos na propulsão de movimentos no discurso.

\section{Considerações Finais}

Buscamos, neste trabalho, ao analisarmos a charge "Da FEBEM para o presídio", refletir acerca do modo como sentidos sobre os sujeitos do crime são constituídos e apontam para uma falha/falta do Estado e para uma violência contra crianças e adolescentes infratores.

A teorização e o recorte de análise aqui apresentados indiciam os movimentos do sujeito em dizeres nos quais o sentido está dado por (um) fio(s), o fio do desejo (e do possível de desejar) e o fio do discurso (efeito de sentidos para sujeitos interpelados ideologicamente); fios esses cheios de furos, equívocos e deslizamentos para os quais não existe obturação plena, tampouco fechamento da significação. Os sujeitos do crime fazem escancarar essa condição, gritando que "alguma coisa está fora da ordem, fora da nova ordem mundial”.

\section{Referências}

ANGELI. Da FEBEM para o presídio. (2005). Folha de S. Paulo, São Paulo, p. A-2, 16 mar. 2005.

ATHAYDE, C.; BILL, MV. Documentário Falcão - Meninos do tráfico. Áudio e vídeo gravados do Programa Fantástico da Rede Globo de televisão, exibido em 19 mar. 2006. 
AUTHIER-REVUZ, J. Palavras incertas: as não coincidências do dizer. Campinas: UNICAMP, 1998.

ALTHUSSER, L. Ideologia e Aparelhos ideológicos de Estado (Notas para uma investigação). In: ZIZEK, S. (Org.). Um mapa da Ideologia. Tradução de Vera Ribeiro. Rio de Janeiro: Contraponto, 1996.

BAIRRÃO, J. F. M. H. O impossível sujeito: implicações da irredutibilidade do inconsciente. v. 1. São Paulo: Edições Rosari, 2003.

CAZARIN, E. A. A heterogeneidade discursiva de uma posição-sujeito. In: SEMINÁRIO DE ESTUDOS EM ANÁLISE DO DISCURSO, 2., 2005, Porto Alegre. Anais eletrônicos... Porto Alegre: UFRGS, 2005. Disponível em: <http://www.discurso.ufrgs.br/sead2/doc/ sujeito/ercilia.pdf>. Acesso em: 19 fev. 2018.

FEFFERMANN, M. Vidas arriscadas: o cotidiano dos jovens trabalhadores do tráfico. Petrópolis: Vozes, 2006.

FERreirA, A. B. H. Novo Dicionário Aurélio da Língua Portuguesa. Rio de Janeiro: Editora Nova Fronteira, 1986.

FERREIRA, M. C. L. A trama enfática do sujeito. In: SEMINÁRIO DE ESTUDOS EM ANÁliSE DO DISCURSO, 2., 2005, Porto Alegre. Anais eletrônicos... Porto Alegre: UFRGS, 2005.2 Disponível em: <http://www.discurso.ufrgs.br/sead2/doc/sujeito/Maria_cristina.pdf>. Acesso em: 19 fev. 2018.

FREUD, S. [1907]. O delírio e os sonhos na Gradiva de W. Jensen. In: Edição Standard brasileira das Obras Completas de Sigmund Freud. v.5. Rio de Janeiro: Imago Editora, 1996.

FURTADO, T. H. As lacunas de sentido no discurso jornalístico: do repórter ao editor da Revista VEJA. Dissertação (mestrado). Universidade Federal do Rio Grande do Sul, Porto Alegre, 2000.

LACAN, J. [1964]. O seminário, livro 11: os quatro conceitos fundamentais da psicanálise. Rio de Janeiro: Jorge Zahar Ed., 1998.

ORLANDI, E. P. A linguagem e seu funcionamento: as formas do discurso. 2. ed. Campinas: Pontes, 1987.

ORLANDI, E. P. Análise de Discurso: princípios e procedimentos. 6. ed. Campinas: Pontes, 2005.

PATTI, A. R.; ROMÃO, L. M. S. Sentidos de criança: filhos e netos do tráfico no movimento do discurso. In: MILANEZ, N.; GASPAR, N. (Org.). Ordem e desordem no discurso. Bahia: UFBA, 2008.

PÊCHEUX, M. [1975]. Semântica e discurso: uma crítica à afirmação do óbvio. Tradução de Eni P. Orlandi. Campinas: UNICAMP, 1988. 
PÊCHEUX, M. Análise Automática do Discurso. In: GADET, F.; HAK, T. (Org). Por uma análise automática do discurso. Campinas: UNICAMP, 1990.

VIEIRA, M. A. Restos: uma introdução lacaniana ao objeto da psicanálise. Rio de Janeiro: Contra Capa, 2008.

Recebido em: 4 de março de 2019.

Aceito em: 2 de maio de 2019. 